$\begin{array}{ll}\text { Abstracta Iranica } & \begin{array}{l}\text { Abstracta Iranica } \\ \text { Revue bibliographique pour le domaine irano-aryen }\end{array} \\ & \text { Volume } \mathbf{3 7 - 3 8 - 3 9} \text { | } 2018 \\ \text { Comptes rendus des publications de 2014-2016 }\end{array}$

\title{
Matteo De Chiara, Evelin Grassi (eds.). Iranian Languages and Literatures of Central Asia. From the eighteenth century to the present
}

\author{
Marc Toutant
}

\author{
(2) OpenEdition \\ Journals \\ Édition électronique \\ URL : http://journals.openedition.org/abstractairanica/47361 \\ DOI : 10.4000/abstractairanica.47361 \\ ISBN : 1961-960X \\ ISSN : 1961-960X \\ Éditeur : \\ CNRS (UMR 7528 Mondes iraniens et indiens), Éditions de l'IFRI
}

\section{Référence électronique}

Marc Toutant, « Matteo De Chiara, Evelin Grassi (eds.). Iranian Languages and Literatures of Central Asia.

From the eighteenth century to the present », Abstracta Iranica [En ligne], Volume 37-38-39 | 2018,

document 2, mis en ligne le 30 décembre 2018, consulté le 28 septembre 2020. URL : http://

journals.openedition.org/abstractairanica/47361; DOI : https://doi.org/10.4000/abstractairanica. 47361

Ce document a été généré automatiquement le 28 septembre 2020.

Tous droits réservés 


\title{
Matteo De Chiara, Evelin Grassi (eds.). Iranian Languages and Literatures of Central Asia. From the eighteenth century to the present
}

\author{
Marc Toutant
}

\section{RÉFÉRENCE}

Matteo De Chiara, Evelin Grassi (eds.). Iranian Languages and Literatures of Central Asia. From the eighteenth century to the present. Paris : Association pour l'Avancement des Etudes Iraniennes, 2015, 336 p. + index, ISBN : 978-2-910640-43-9 (Cahiers de Studia Iranica 57)

1 Dans le premier volet de cet ouvrage collectif, sont abordées les questions liées à la classification du pashto, à ses emprunts lexicaux aux idiomes turciques et mongols, à l'étude de son vocabulaire phraséologique, et aux divergences que l'on peut remarquer entre l'appartenance ethnique de ses locuteurs et leurs comportements linguistiques. La situation du bukhorī, la langue des juifs boukhariotes, est évoquée à la lumière d'une étude menée dans le Queensistan (New York); tandis qu'une autre contribution rapproche le "persan timouride» du tadjik d'aujourd'hui en prenant appui sur un glossaire persan-chinois de la période ming. Si l'on replace les contributions du second volet dans l'ordre chronologique, il est possible de suivre plusieurs aspects de l'évolution de la littérature tadjike, notamment à travers la mutation de ses genres (ghazal), depuis la phase réformiste (jadid) jusqu'à la période contemporaine marquée par le poids du legs soviétique en dépit des proclamations de " renouveau islamique ».

2 Le compte-rendu détaillé de l'ouvrage est paru dans Studia Iranica 47, 2018. 


\section{AUTEURS}

MARC TOUTANT

CNRS - CETOBAC 